\title{
MATEMÁTICA NA EDUCAÇÃO INFANTIL: CONTRIBUIÇÕES DA ATIVIDADE ORIENTADORA DE ENSINO PARA A (RE)ORGANIZAÇÃO DA PRÁTICA DOCENTE
}

\author{
GISELE MENDES AMORIM \\ VANESSA DIAS MORETTI \\ Universidade Federal de São Paulo (UNIFESP), Guarulhos, São \\ Paulo, Brasil
}

\begin{abstract}
RESUMO: O objetivo desta pesquisa foi investigar as contribuições do conceito de Atividade Orientadora de Ensino como desencadeador da mudança de prática docente na Educação Infantil, na organização do ensino de noções matemáticas. O referencial teórico é a psicologia Histórico-Cultural, a Teoria da Atividade e o conceito de Atividade Orientadora de Ensino. Partindo de um contexto escolar, no qual as professoras desenvolviam atividades matemáticas pautadas apenas em situações cotidianas e repetidas, foi desenvolvido um experimento didático para acompanhar o movimento de aprendizagem docente. Os resultados indicam a potencialidade do conceito de Atividade Orientadora de Ensino como propiciador de mudança da prática docente a partir de nova organização do ensino da matemática na Educação Infantil.

Palavras-Chave: Educação matemática. Psicologia histórico-cultural. Formação de professores. Educação infantil.
\end{abstract}

MOTIVAÇÃO PARA A PESQUISA E OBJETIVO

O interesse em tomar como objeto de pesquisa e investigação a Educação Matemática e, em particular, como o processo de ensino e de aprendizagem da matemática é realizado nas escolas de Educação Infantil, 
surgiu da observação escolar cotidiana acerca da dificuldade que costuma ser vivenciada por grande parte dos professores que atuam nessa etapa da educação, em relação à essa área do conhecimento. No contexto escolar específico, no qual se desenvolveu a parte empírica dessa pesquisa, a análise do processo de avaliação coletiva do plano de ação 2013 da instituição escolar evidenciou-se a necessidade de aprimoramento das discussões sobre a prática docente em torno do eixo de matemática na Educação Infantil. Naquele momento, as professoras apresentavam dificuldades em planejar situações significativas para a exploração de noções matemáticas de forma lúdica e contextualizada, limitando tal abordagem às noções de cores e números, focadas em uma abordagem cotidiana e utilitária dos conceitos por meio de exercícios de repetição e memorização.

Em busca de compreender mais profundamente essa realidade e algumas possibilidades de superação das dificuldades apontadas pelas professoras enveredamos para o estudo dos referenciais teóricos da Psicologia Histórico-Cultural proposta por Vigotski (2007, 2009), da Teoria da Atividade desenvolvida por Leontiev $(1983,2012)$ e do conceito de Atividade Orientadora de Ensino (AOE) proposto por Moura (1996, 2010). Apoiados nesses estudos, o objetivo dessa pesquisa foi investigar a potencialidade do conceito de Atividade Orientadora de Ensino - AOE (MOURA, 1996, 2010) como propiciador do movimento de mudança da prática docente, a partir de uma nova organização do ensino da matemática na educação infantil.

Neste texto, apresentamos a síntese da fundamentação teórica da pesquisa desenvolvida, sua forma de organização e metodologia e a análise dos isolados (CARAÇA, 1951) investigados, bem como as considerações e conclusões decorrentes.

Teoria Histórico-Cultural e Teoria da Atividade: contribuições para a EDUCAÇÃO INFANTIL

Buscando melhor compreender as especificidades do nosso objeto de pesquisa apoiamo-nos no referencial da Teoria Histórico-Cultural (VIGOTSKI, 2007, 2009), em particular na Teoria da Atividade (LEONTIEV, 1983, 2012). Esses referenciais trazem contribuições na explicitação de elementos do processo de humanização e desenvolvimento infantil, bem como permite compreender o movimento de aprendizagem dos professores em atividade de ensino, como veremos na sequência.

A psicologia histórico-cultural surge da busca de Vigotski (2007) em superar as correntes idealista e mecanicista, vigentes na psicologia no começo do século XX. Segundo Luria (2012, p. 25), Vigotski 
[...] concluiu que as origens das formas superiores de comportamento consciente deveriam ser achadas nas relações sociais que o indivíduo mantém com o mundo exterior. Mas o homem não é apenas um produto do seu ambiente, é também um agente ativo no processo de criação deste meio.

Desta forma, as relações sociais são tomadas como pressuposto fundamental para o processo de aprendizagem e desenvolvimento humano na perspectiva histórico-cultural, uma vez que o processo de aprendizagem "pressupõe uma natureza social específica e um processo através do qual as crianças penetram na vida intelectual daqueles que a cercam" (VIGOTSKI, 2007, p. 100). Vigotski propõe que a aprendizagem deve estar à frente do desenvolvimento, de modo a atuar na zona de desenvolvimento proximal, que caracteriza o desenvolvimento psíquico prospectivamente e que "permite-nos delinear o futuro imediato da criança e seu estado dinâmico de desenvolvimento, propiciando o acesso não somente ao que já foi atingido através do desenvolvimento, como também àquilo que está em processo de maturação" (VIGOTSKI, 2007, p. 98).

Considerando o homem como um ser social, cujas funções do desenvolvimento humano aparecem primeiramente no nível social (interpsíquico), e posteriormente no nível individual (intrapsíquico) (VIGOTSKI, 2007), justifica-se a importância do trabalho pedagógico para o desenvolvimento humano que se estabelece por meio do processo de aprendizagem, intencional e planejado, com vistas ao desenvolvimento do sujeito. Tal processo de conhecimento não se dá de forma direta entre o sujeito e o objeto de conhecimento, mas sempre de forma mediada, por meio de um signo ou instrumento, de modo que o conceito de mediação implica a ideia de que o homem é capaz de operar mentalmente sobre o mundo.

Nesta perspectiva, a escola é compreendida como local privilegiado de apropriação dos conhecimentos historicamente constituídos, onde a organização intencional do acervo cultural produzido historicamente representa a essência do trabalho docente, considerada como atividade principal do professor, pois

[...] se, dentro da perspectiva histórico-cultural, o homem se constitui pelo trabalho, entendendo este como uma atividade humana voltada a um fim e orientada por objetivos, então o professor constitui-se professor pelo seu trabalho - atividade de ensino - ou seja, o professor constitui-se professor na atividade de ensino (MORETTI, 2007, p. 101).

Como consequência, a formação docente continuada, ancorada na perspectiva histórico-cultural, desencadeia-se por necessidades pedagógicas 
que impulsionam o professor a modificar ou qualificar o seu trabalho com a finalidade de organizar o processo de ensino, de forma a desenvolver nas crianças as máximas capacidades humanas, tendo como referência os conhecimentos historicamente constituídos pela humanidade (AMORIM, 2015).

Tais necessidades podem ser compreendidas como premissa para a atividade de ensino uma vez que, de acordo com Leontiev (2012), toda atividade nasce de uma necessidade e dirige-se a um objetivo que se transforma no motivo dessa atividade. Desta forma, a necessidade pedagógica apresenta-se como "mola" propulsora para a atividade de ensino, que por sua vez relaciona-se com os motivos que remetem às ações pedagógicas direcionadas a objetivos.

Assim, por exemplo, se o professor tem por objetivo que as crianças se apropriem do conceito de número e compreendam o sistema de numeração decimal em seu movimento lógico-histórico, essa necessidade pedagógica passa a mobilizá-lo a desenvolver ações condizentes com seu objetivo e sua atividade de ensino passa a se constituir por meio da apropriação do conceito de número, assim como dos meios necessários para propiciar às crianças essa apropriação. Para tanto, "um elemento essencial na formação do professor é o conhecimento da história dos conceitos, pois essa história é a história do desenvolvimento dos problemas e das soluções criadas nas relações humanas" (MOURA, 2012, p. 188). A partir da necessidade pedagógica de colocar o conhecimento a ser aprendido como uma necessidade para aquele que aprende e fundamentado no conhecimento do movimento lógico-histórico do conceito, o professor "lançará mão de instrumentos e de estratégias que lhe permitirão uma maior aproximação entre sujeitos e objeto de conhecimento" (MOURA, 1996, p. 4), criando situações desencadeadoras de aprendizagem.

\section{EducaÇÃo MatemÁtica na InFÂNCIA}

Reconhecer os conceitos matemáticos como produção humana constituída historicamente a partir de necessidades sociais implica organizar o ensino, considerando esse movimento de produção e a necessidade que o moveu. Assim, por exemplo, o sistema de numeração decimal em sua complexidade, embora tenha sua presença no cotidiano "teve seu início na pré-história, [quando] o ser humano utilizou diferentes estratégias para controlar, registrar e comunicar as quantidades, bem como para realizar cálculos e operações" (MOURA, 1996, p. 1). Pensar sobre a produção desse sistema é pressuposto básico para a apropriação do conhecimento de número, 
o que diverge totalmente da apropriação do número de forma mecânica, por meio de memorização.

O ensino da matemática na educação infantil pressupõe a participação da criança como sujeito ativo em sua complexidade, tanto no aspecto cognitivo quanto corporal, o que transcende a função motora exercida em uma atividade de grafia de numerais resultantes da contagem de um conjunto de objetos. Além disso, o conceito de número é constituído de elementos que superam a mera grafia numérica, tais como a correspondência um a um, a

[...] cardinalidade, ordinalidade, contagem seriada, contagem por agrupamento, composição e decomposição de quantidade, reconhecimento de símbolos, representação numérica, operacionalização numérica, percepção de semelhanças e diferenças, percepção de inclusão e percepção de invariância (LORENZATO, 2008, p. 31-32).

Assim, por exemplo, embora a identificação dos números em calendário e contagem de rotina revelem a função social do número e sua utilidade, cabe à escola ampliar a experiência cotidiana e organizarse objetivando o acesso aos bens culturais constituídos historicamente. A implicação dessa postura pedagógica para a abordagem do sistema de numeração na educação infantil passa por compreender que, embora as crianças ingressem na escola com certo conhecimento sobre números, isso não significa a apropriação deste complexo sistema e dos elementos que o compõem, decorrendo daí a importância do trabalho do professor na organização das práticas em educação matemática, na seleção dos conceitos e nas formas de se abordar esses conhecimentos. Nesse sentido, temos na Atividade Orientadora de Ensino (AOE) (MOURA, 1996, 2010), um conceito orientador da organização do ensino da matemática, ao propor o desenvolvimento de atividades desencadeadoras de aprendizagem que contenham a síntese histórica do conceito, os recursos teóricos metodológicos do processo de apropriação do conceito e a análise e a síntese da solução coletiva, mediada pelo professor. Tal conceito, que tem apoiado diferentes pesquisas sobre a formação de professores que ensinam matemática (MOURA, 1996; ARAUJO, 2003; MORETTI, 2007; CEDRO, 2008; RIBEIRO, 2011), foi tomado também como norteador das ações de formação desenvolvidas na pesquisa relatada nesse artigo e, como já enunciado, constituiu-se como nuclear na delimitação da questão de investigação. 


\section{A METODOLOGIA DE COLETA E ANÁLISE DE DADOS}

Partindo do objetivo já indicado de investigar a potencialidade do conceito de AOE como propiciador do movimento de mudança da prática docente, a partir de uma nova organização do ensino da matemática na educação infantil, desenvolvemos, em 2014, um experimento didático em uma escola municipal de educação infantil na cidade de Guarulhos, na região da grande de São Paulo. O método do experimento didático (MOURA; CEDRO, 2012) apoia-se no princípio de investigar o objeto em movimento (VIGOTSKI, 2007) e constitui-se como uma interessante possibilidade metodológica na pesquisa em educação matemática, por se apresentar como

[...] método de investigação psicológica que permite estudar a essência das relações internas entre os diferentes procedimentos da educação e do ensino e o correspondente caráter de desenvolvimento psíquico do sujeito (MOURA; CEDRO, 2012, p. 31).

O experimento didático organizou-se em encontros semanais realizados em hora-atividade - momento de trabalho coletivo de professores na escola e possibilitou acompanhar o desenvolvimento da atividade docente de modo a compreender a gênese da mudança ou ressignificação da prática docente a partir da apropriação pelos professores do conceito de AOE (MOURA, 1996, 2010). Nos encontros formativos, focou-se na exploração do conceito de número em seus aspectos lógico-histórico, como forma de ampliar possibilidades para a organização de ações docentes voltadas à educação matemática das crianças ao permitir aos professores

Reconhecer esse movimento lógico-histórico de construção não linear do conhecimento matemático, que se contrapõe ao que por vezes é apresentado tradicionalmente no ensino, e concebê-lo como parte de seu trabalho na organização do ensino [...] (DIAS; MORETTI, 2011, p. 11).

Tanto a organização dos diferentes encontros e ações que constituíram o experimento didático quanto à análise dos dados, fundamentou-se no conceito de Atividade Orientadora de Ensino elaborado por Moura $(1996,2010)$, sustentado pela Teoria da Atividade (LEONTIEV, 1983, 2012), em coerência com a perspectiva histórico-cultural (VIGOTSKI, 2007, 2009).

O acompanhamento sistemático de oito professoras em 27 encontros didáticos (E.D.) resultou em um acervo de dados coletados por meio de conversas individuais, planos de aula, atividades desenvolvidas com as crianças, análise das atividades realizadas, socialização das atividades produzidas e relatórios individuais (R.I.), além do diário de campo da 
formadora-pesquisadora, com registros de observação dos encontros didáticos. Respeitando o anonimato dos participantes, nomeamos as professoras de forma fictícia e, na sequência de cada excerto dos dados, indicamos as iniciais da sua fonte.

Os dados coletados foram analisados com base nos princípios do método histórico-dialético visando explicar as contradições e superações manifestas no processo formativo. Para isso, a análise do movimento mediado dos diferentes sentidos manifestos pelas professoras, na relação entre o particular e geral, buscou não apenas descrever tal movimento, mas explicá-lo no processo de superação de comportamentos fossilizados por meio da atribuição de novos sentidos. Os comportamentos fossilizados são entendidos como "comportamentos mecanizados ou automatizados que perderam sua origem ao longo do tempo" (VIGOTSKI, 2007, p. 68) os quais não permitem estudar um fenômeno dialeticamente, uma vez que "é somente em movimento que um corpo mostra o que é" (VIGOTSKI, 2007, p. 68). Para tanto, os dados foram categorizados em isolados (CARAÇA, 1951) e em episódios (MOURA, 2004). Segundo Caraça (1951), os isolados podem ser compreendidos como uma

[...] secção da realidade, nela recortada arbitrariamente [...] de modo a compreender nele todos os fatores dominantes, isto é, todos aqueles cuja acção [sic] de interdependência influi sensivelmente no fenômeno a estudar (CARAÇA, 1951, p. 112).

Já os episódios permitem o detalhamento do isolado de modo que "revelam a natureza e qualidade das ações em um isolado" (MOURA, 2004, p. 273). Buscando revelar indícios do movimento de mudança da prática docente decorrente da apropriação do conceito de AOE os dados analisados foram organizados em três isolados: Conceitos Matemáticos em Movimento; Mediação como elemento fundamental para ensinar e aprender Matemática; e Organização do Ensino da Matemática na Educação Infantil. Alguns deles foram detalhados em episódios, os quais apresentaremos a seguir.

Professores em Atividade de Ensino: conceitos matemáticos em moviMENTO

Isolado 1: Conceitos Matemáticos em Movimento

O primeiro isolado de análise foi organizado em dois episódios: I Discussões iniciais sobre o processo de ensino da matemática na educação infantil; II - O Segredo da Canastra. 
O primeiro episódio evidencia os motivos das professoras em participar da formação continuada e suas expectativas em relação à formação com vistas à atuação pedagógica, o que revelou uma prática pautada em conhecimentos empíricos resultantes de situações cotidianas por meio de exercícios de repetição, conforme relata a professora Eva:

Na educação infantil acabamos trabalhando a matemática na rotina não elaborando uma atividade específica (EVA, ED 01).

Já o relato da professora Bia, demonstrou a compreensão de que a matemática está presente nas brincadeiras e em ações cotidianas, mas questionou como explorar os conceitos decorrentes destas situações:

Penso que trabalhamos matemática todo tempo, mas como chamar a atenção da criança sobre o fato daquela atividade ser matemática.... por exemplo, numa brincadeira de pega-pega eu trabalho espaço, mas como evidenciar isso para o aluno ou levar essa prática para meus registros? (BIA, ED 01).

A partir dos relatos das professoras vimos a necessidade de colocálas diante de uma situação que oportunizasse a apropriação de conceitos matemáticos como produto de um processo histórico e cultural a partir da necessidade humana. Nessa perspectiva é que desenvolvemos a história virtual "O Segredo da Canastra" (AMORIM, 2015, p.113), inspirada em uma situação desencadeadora de aprendizagem denominada "Carta dos Caitités" (MOURA, 1996). A história virtual "O Segredo da Canastra" cria um contexto no qual a personagem Emília, do Sítio do Pica-Pau Amarelo, guarda um segredo na sua canastra e a fecha com um cadeado numérico. Para não esquecer a senha, Emília deixa algumas pistas relacionando símbolos arbitrários com os algarismos indo-arábicos. A resolução consiste em descobrir a lógica do sistema de numeração fictício, de base quatro. Sua elaboração teve por objetivo problematizar o sistema de numeração decimal de forma lúdica, explicitando alguns dos elementos que o compõem e envolver as professoras na resolução coletiva dessa situação-problema com vistas à apropriação ou ressignificação desse sistema numérico.

Na resolução da situação desencadeadora de aprendizagem algumas professoras se revelaram tensas, relatando que seria impossível resolver o problema; outras professoras tentaram equivaler os símbolos contidos na situação por números do sistema de numeração decimal, desconsiderando a base numérica, o que não propiciou a compreensão do sistema de numeração fictício de base quatro. Após algumas tentativas as professoras perceberam a regularidade de variação de símbolos, a base do sistema e a importância do valor posicional do símbolo equivalente ao número zero, de forma análoga ao 
sistema de numeração decimal. O compartilhamento da solução da situação desencadeadora de aprendizagem entre as professoras revelou o movimento dos significados do conceito de sistema de numeração, compartilhados pelo grupo, como podemos identificar nos relatos das professoras Camila e Eva:

Esse processo de entender como funciona o sistema de numeração decimal também nos leva a pensar como a gente ensina para a criança, para trabaIhar com o sistema de numeração de base quatro, houve a necessidade de desconstruir conceitos já concretizados (CAMILA, ED 03).

Essa exploração do sistema de numeração não acontece nem no ensino fundamental (EVA, ED 03).

Esse não seria um dos motivos pelos quais as crianças possuem dificuldade em matemática? (CAMILA, ED 03).

Isso me fez pensar o quanto foi complexa a construção do sistema de numeração que hoje utilizamos e ainda como podemos trabalhar esse conhecimento, essa história com as crianças (EVA, ED 03).

Embora no episódio I as professoras tivessem indicado não terem dificuldade com a matemática e seu ensino, no episódio II, diante da necessidade do conceito, elas ressignificam seus conhecimentos ao se depararem com um sistema de numeração com base diferente da habitual. Esse movimento de ressignificação do conceito de sistema de numeração só foi possível via a apropriação conceitual, elemento essencial na atividade de ensino. Ao se apropriar de elementos dos conceitos de sistema de numeração em sua gênese e modos de constituição, as professoras passaram a questionar seus modos de organizar o ensino, o que não havia se dado espontaneamente apenas por meio de uma prática pautada na aparência, e não na essência, do conceito. Nesse processo de formação contínua dá-se a apropriação tanto dos conceitos a serem ensinados quanto dos meios para ensinar, direcionando-os às ações planejadas e conscientes num movimento de reversão de ações ou comportamentos fossilizados.

Isolado 2: A mediação como elemento fundamental para ensinar e aprender matemática

Se por um lado a apropriação do conceito de número em seu movimento lógico-histórico não decorre de um contato empírico como conceito, por outro lado dá-se em um processo mediado. Para Vigotski (2007, 
2009), o traço fundamental do psiquismo humano é que este se desenvolve por meio da atividade social, que por sua vez se dá pela mediação dos signos e instrumentos que se interpõem entre o sujeito e o objeto de conhecimento, ou seja, a apropriação do acervo cultural produzido pela humanidade ocorre na atividade humana de forma mediada. Uma implicação desse pressuposto no processo de formação docente, é que os professores se apropriam de conceitos a serem ensinados em atividade de ensino, considerando que ao elaborar uma situação desencadeadora de aprendizagem o professor coloca em ação os seus conhecimentos, conceituais e didáticos, acerca do objeto a ser trabalhado, ressignificando-os no espaço coletivo. Com objetivo de explicitar indícios de aprendizagem docente acerca da mediação no processo de ensino e a qualidade dessa mediação, revelada como ação intencional do professor em atividade de ensino, o isolado 2 "Mediação como elemento fundamental para ensinar e aprender matemática" foi organizado em dois episódios: I - Jogo do Boliche e II - No tempo das Trocas.

O episódio "Jogo do Boliche" evidencia o movimento da professora Bia na organização, desenvolvimento, discussão coletiva e reorganização da situação desencadeadora de aprendizagem desenvolvida a partir do texto "Controle de variação de Quantidades" (MOURA, 1996), que apresenta propostas didáticas para a abordagem do conceito de número na educação infantil a partir do conceito de atividade orientadora de ensino. 0 jogo foi selecionado coletivamente por três professoras para ser desenvolvido junto às crianças de quatro e cinco anos, no entanto, a professora Bia antecipou-se em desenvolver o jogo com sua turma, antes mesmo da leitura e discussão coletiva do texto de Moura (1996).

Durante a socialização, Bia relatou ter organizado o jogo com sua turma de modo que uma das crianças marcava, com a ajuda da professora auxiliar, a quantidade de peças derrubadas pelos jogadores. Diante deste relato, a formadora retomou o conceito de mediação como elemento fundamental no processo de apropriação do mundo pela criança, ressaltando que a organização da dinâmica do jogo e o registro de pontos realizado por cada criança poderiam ter criado a oportunidade da professora atuar intencionalmente de forma a problematizar, dialogar e compartilhar com as crianças situações como a quantidade de pinos derrubados, as diferentes possibilidades de se representar e registrar uma determinada quantidade, estratégias de cálculo, entre outros. Neste sentido, Moura (1996, p. 24) apresenta a importância do professor observar as ações das crianças durante o jogo e a evolução das estratégias de registro e contagem, para que possa intervir adequadamente no processo de aprendizagem. A antecipação 
da professora demonstrou tanto o envolvimento e ansiedade em iniciar a atividade prática, quanto revelou a ideia de que não há necessidade de aprofundamento teórico, planejamento e discussão coletiva para desenvolver um jogo com as crianças.

Num segundo relato, Bia descreveu ter reorganizado o jogo de boliche de modo que cada criança registrasse seus pontos colocando risquinhos; porém, deparou-se com uma criança que preferiu registrar com algarismos indo-arábicos. A partir dessa situação, a professora deixou de indicar a forma de registro, deixando que as crianças registrassem livremente os pontos e observou que houve diferentes formas de registro, pois as crianças registraram por meio de risquinhos, algarismos e desenho dos pinos do boliche. Se na primeira rodada do jogo de boliche, a professora estabeleceu uma padronização de registro de pontos (risquinhos) e, posteriormente, permitiu que cada criança registrasse a quantidade de pontos, de acordo com suas experiências, valendo-se dessa oportunidade para dialogar com a turma sobre as diferentes formas de registro utilizadas pelo homem antes da criação do sistema de numeração decimal, vemos indícios de que Bia apropriou-se de elementos do conceito de AOE e, também, de elementos do conceito de número numa perspectiva histórico-cultural, impactada pela aprendizagem docente do conceito de mediação como elemento fundamental para aprender e ensinar matemática. Ao apresentar o desenvolvimento do jogo de boliche reorganizado, Bia relatou:

Fiz muitos cursos que elegem a brincadeira como um direito da criança, será que nós temos o direito de entrar na brincadeira das crianças com esse monte de questionamento, de cima para baixo? Por outro lado, tenho percebido um efeito muito positivo no desenvolvimento das crianças após a utilização dos jogos, as crianças se interessaram pelo jogo, se desenvolveram na questão da sequência numérica [...] (BIA, R.I. 22).

Neste episódio, Bia revela indícios de mudança de sentido sobre o brincar. Se inicialmente acreditava que o brincar livre seria suficiente para a aprendizagem de conceitos matemáticos, conforme exposto no item "Conceitos matemáticos em movimento", com a apropriação e desenvolvimento do conceito de AOE passou a identificar a importância da organização do processo de ensino e da mediação docente no processo de aprendizagem das crianças. Tal mudança aponta indícios de transformação de motivo, compreendida pelo fato do "resultado da ação ser mais significativo, em certas condições, que o motivo que realmente a induziu" (LEONTIEV, 2012, p. 70), ou seja, ao identificar que o desenvolvimento do jogo possibilitou a aprendizagem das crianças sobre sequência numérica, a professora Bia passou 
a rever suas ações e a se apropriar do jogo e da $A O E$, que de forma mediada se constituem como elementos capazes de desenvolver a aprendizagem de noções matemática na infância.

A professora Bia revelou, por meio de seus relatos, a preocupação com o brincar como direito da criança e eixo central do processo de aprendizagem da educação infantil. De fato, tal importância é indiscutível, posto que compartilhamos da compreensão de que ao brincar a criança se apropria de conceitos morais e sociais, se socializa, aprende a respeitar o outro, se autorregula e se comunica, ou seja, se apropria da atividade humana, pois, na tentativa de agir como o adulto, ela esforça-se para atuar de forma superior à que é inerente à sua idade, e desta forma o brincar atua na zona de desenvolvimento proximal (VIGOTSKI, 2007, 2009).

Vimos nos relatos expostos por Bia, a divergência encontrada pela professora entre o brincar livremente e a utilização de situações lúdicas no processo de ensino e aprendizagem do conceito de número; divergência que foi sendo superada a partir da percepção do resultado de sua ação (LEONTIEV, 2012). No caso de Bia, a utilização do recurso teórico-metodológico, apresentado na $A O E$, possibilitou às crianças a apropriação da sequência numérica o que, por sua vez, respondia às necessidades pedagógicas da professora e ao motivo da sua atividade. Nesse processo de avaliação do resultado da ação e revisão do motivo, gradativamente transforma-se a atividade de ensino. A superação da divergência indicada foi observada tanto na reorganização do jogo de boliche quanto na discussão coletiva propiciada pela apresentação de outras professoras da história virtual "No tempo das Trocas" (episódio II).

Ao participar da apresentação do desenvolvimento da situação desencadeadora de aprendizagem "No tempo das Trocas" pelas professoras que atuavam em salas com crianças na faixa etária de quatro a cinco anos, Bia colocou-se de forma a transparecer seu incômodo em relação ao vídeo apresentado pela professora Ana, e relatou que percebia uma preocupação excessiva de algumas colegas professoras em apresentar vídeos e trabalhos perfeitos, nos quais a atividade tinha "dado certo". No entanto, os apontamentos feitos por Bia acabaram provocando certo alvoroço nas demais professoras, momento em que a professora Ana questionou:

Então como deve ser a intervenção realizada? (ANA, ED 21). Não tenho a resposta, mas se eu não puder falar o que penso... Somos um grupo e estamos aqui para aprender, se trouxer só aquilo que deu certo fica fácil, tenho uma série de dúvidas e acredito que este é o lugar para discussões... (BIA, ED 21). 
O conflito que se explicitou por meio dessa discussão revela a coexistência de diferentes sentidos que permeiam o ambiente educativo. O sentido de uma aprendizagem individual, que prevê uma organização do ensino que privilegia o processo de aprendizagem individual por meio do contato direto da criança com o objeto de conhecimento utilizando para tanto, da apresentação, repetição e memorização do conceito. $O$ sentido de aprendizagem espontânea, que prevê uma organização do ensino que privilegia a organização de um ambiente que possibilite as interações entre as crianças por meio do brincar livre em que as aprendizagens podem surgir nessas situações não planejadas. $O$ sentido de uma aprendizagem na perspectiva da Atividade, que prevê uma organização intencional e planejada do ensino, que privilegia o brincar como foco central do processo de ensino, por compreender que esta é atividade principal da criança e por isso impulsiona sua aprendizagem e desenvolvimento, enquanto o planejamento e desenvolvimento das situações-problema são realizados com vistas a envolver a criança num movimento de apreensão da gênese dos conceitos numa perspectiva histórico-cultural. O terceiro sentido citado é o defendido neste trabalho, por compreender que o processo de ensino e aprendizagem se dá em atividade. Estes sentidos de como a criança aprende e se desenvolve determinam a forma de organizar o processo de ensino e, também, estão presentes no ambiente escolar, sendo, muitas vezes, silenciados e não discutidos.

Assim, embora no Isolado I, Bia tenha indicado organizar o processo de ensino, de modo a privilegiar um ambiente que possibilitasse as interações entre as crianças por meio do brincar livre, objetivando que as aprendizagens surgissem dessas situações não planejadas, em um segundo momento a professora pareceu oscilar nessa convicção, à medida que trouxe suas dúvidas para o grupo.

As argumentações que estou fazendo não são apenas apontamentos para as colegas, faço uma autocrítica, pois fiquei assustada quando me enxerguei no vídeo, me achei muito incisiva, muito autoritária. É preciso rever nosso posicionamento na dinâmica com as crianças. (BIA, ED 22).

Tal relato revela indícios da mudança de sentido da professora Bia acerca das mediações no processo de ensino. Com esta argumentação, a professora parece rever sua prática, impactada pela observação das ações de outras professoras no desenvolvimento de situações desencadeadoras de aprendizagem. Nesse contexto, retomamos a importância do outro na formação e desenvolvimento do sujeito, uma vez que compreendemos, em 
coerência com o referencial teórico adotado, que o desenvolvimento psíquico se estabelece por meio das relações com o outro e com o meio social, em um movimento do inter para o intrapsíquico.

\section{Isolado 3: Organização do Ensino da Matemática na Educação Infantil}

Se inicialmente a organização do processo de ensino da matemática, na escola em que foi realizada a pesquisa empírica, refletia um olhar docente voltado às aprendizagens derivadas de situações cotidianas e brincadeiras livres, ao longo do processo formativo, tendo como pressuposto a Teoria histórico-cultural e o brincar como atividade principal das crianças (LEONTIEV, 2012), deparamo-nos com um processo de ensino totalmente repensado e replanejado, uma vez que o ensino e aprendizagem de conceitos matemáticos foi ressignificado pelas professoras.

O Isolado "Organização do Ensino da Matemática na Educação Infantil", composto pelos episódios I - Contagem de rotina e II - O galinheiro da Tia Nastácia, apresenta indícios dessa ressignificação conceitual e didática. Para os fins deste artigo, nos deteremos na análise do primeiro episódio que possibilita o acompanhamento do movimento de mudança de prática da professora Bia, apresentada anteriormente.

Em um dos primeiros encontros didáticos, Bia relatou ter ficado surpresa ao observar que muitas crianças da sua turma (crianças de quatro anos) não haviam se apropriado da sequência numérica, mesmo com o exercício de contagem diária.

Na semana anterior eu distribuí balas aos alunos e a proposta foi que as crianças deveriam dizer a quantidade de balas que elas queriam e deveriam contar a quantidade de balas solicitadas. Eu estava tentando explorar a sequência numérica com essa situação e me surpreendi em perceber que muitas crianças não haviam se apropriado da sequência de um a dez, mesmo eu fazendo essa contagem diversas vezes por dia, seja na contagem de alunos, na verificação do horário do relógio ou ainda por contar até dez para que as crianças retornassem aos seus lugares na carteira e ao contar as balas muitas crianças pularam a sequência contando um, dois, três, sete (BIA, ED 07).

Com este relato, Bia expressa a não necessária vinculação entre a apropriação de elementos do sistema de numeração decimal com ações repetidas, cujos sentidos não se tornam conscientes para os sujeitos. Tal manifestação de Bia se deu após a tomada de consciência da professora acerca da complexidade desse sistema, o que se deu de forma respaldada pelo experimento didático (Isolado I) e pelas mediações estabelecidas no espaço coletivo. Como consequência, a professora reorganiza o processo de ensino 
de forma consciente, considerando as noções de correspondência biunívoca, agrupamento e comparação de quantidades ao realizar a contagem de crianças presentes de forma pictórica, relacionando na lousa a distribuição de mesinhas dispostas na sala e com a identificação de cada criança por meio da letra inicial de seu nome.

A análise da reorganização das ações da professora Bia apresentou, também, indícios de transformação do motivo que a impulsionava a organizar o processo de ensino sobre sequência numérica. Como já afirmamos, Leontiev (2012) destaca a relação entre o resultado da ação e a transformação do motivo, e complementa que nesse processo "ocorre uma nova objetivação de suas necessidades, o que significa que elas são compreendidas em um nível mais alto" (LEONTIEV, 2012, p. 70).

No primeiro momento, embora houvesse a intenção da professora de que as crianças se apropriassem da sequência numérica, havia de fato uma repetição que não se articulava de forma consciente ao objetivo de apropriação de sequência numérica uma vez que, conforme o relato da professora, as crianças recitavam a sequência numérica sem que tal verbalização fizesse corresponder o numeral com cada criança. Já no segundo momento, a contagem parece ter ganhado uma nova qualidade quando a professora passa a sugerir às crianças estratégias que explorem a correspondência um a um. Assim, quando o sentido das ações da professora se transforma pela tomada de consciência de elementos do sistema de numeração decimal e da importância da mediação no processo de aprendizagem, dá-se a reorganização do ensino no qual passa a ser considerada a noção de correspondência biunívoca. Desta forma, suas ações se tornam conscientes e coerentes com seu objetivo na organização do processo de ensino.

\section{CONCLUSÕES}

As primeiras ações das professoras, voltadas para o ensino de noções do sistema de numeração decimal, podem ser entendidas como comportamentos fossilizados que, "dadas as suas origens remotas, estão agora sendo repetidos pela enésima vez e tornaram-se mecanizados [...] sua natureza externa nada nos diz sobre sua natureza interna" (VIGOTSKI, 2007, p. 68). No entanto, esse comportamento fossilizado parece ter se modificado à medida que as professoras ressignificavam sua compreensão sobre o sistema de numeração decimal e passaram a problematizar a própria prática docente na organização do ensino de matemática na educação infantil, como verificamos nos relatos de Camila e Eva apresentados na análise do Episódio 1, envolvendo a resolução coletiva de "O Segredo da Canastra". 
O comportamento fossilizado pode ser superado por meio da tomada de consciência sobre esse comportamento, o que se dá por meio da reflexão teórica e de ações práticas dos professores em atividade de ensino. No entanto, não se trata de uma reflexão qualquer sobre a prática docente, mas de um processo"mediado por fundamentos ou referenciais que possibilitem a compreensão do objeto no caminho da solução de problemas da prática" (RIBEIRO, 2011, p. 74). No caso da pesquisa aqui relatada, tal reflexão aconteceu pautada pela apropriação conceitual de elementos do sistema de numeração decimal, em um processo de formação continuada ancorado, teoricamente, na abordagem histórico-cultural e, em particular, na Atividade Orientadora de Ensino.

Tal movimento de ressignificação conceitual impulsionou a mudança da prática docente, em decorrência da mudança do sentido atribuído inicialmente ao conceito de número e aos meios de ensiná-lo. Se inicialmente havia entre as professoras a convicção de que o conceito de número poderia ser apresentado às crianças de forma direta por meio de situações cotidianas e exercícios de repetição, a inserção no processo coletivo de formação docente e a apropriação de elementos do conceito de AOE possibilitaram às professoras a reversão de um comportamento que se apresentava fossilizado.

Além da ressignificação conceitual, impactada pelo contato das professoras com um sistema de numeração fictício com base diferente do sistema de numeração decimal, o qual convergiu para a necessidade do conceito desvelando-o em sua gênese, os meios para ensiná-lo foram repensados à medida que uma das professoras percebeu que a recitação ou repetição dos numerais, por meio da contagem rotineira, não propiciou às crianças a apropriação da sequência numérica, uma vez que compreender a sequência numérica passa por apropriar-se da noção de sucessão.

Segundo Vigotski (2009, p. 246), um conceito não pode ser aprendido por mera memorização, uma vez que ele "é mais do que a soma de certos vínculos associativos formados pela memória, é mais que um simples hábito mental; é um ato real e complexo de pensamento." Desta forma, a apropriação de um conceito passa por um ato de pensamento complexo o qual pressupõe a aproximação do sujeito com o objeto de conhecimento de forma mediada, seja pelas interações entre as crianças, com a professora, seja pelo jogo ou pela brincadeira. Na organização do processo de ensino, a mediação se concretiza como ação intencional e planejada do professor em atividade de ensino, cujo objetivo é propiciar às crianças o desenvolvimento das funções psicológicas superiores (VIGOTSKI, 2007, 2009) e a apropriação de noções, conhecimentos, valores etc., formas culturais produzidas historicamente pela humanidade. 
Diante do movimento de aprendizagem conceitual das professoras sobre o sistema de numeração como um conceito derivado de uma necessidade humana que contempla elementos como correspondência um a um, noção de cardinalidade, ordinalidade, agrupamento, composição e decomposição de quantidade, reconhecimento de símbolos e representação numérica, as ações das professoras se alteraram, posto que o objetivo e a necessidade da atividade de ensino se modificaram. Nesse processo, temos que os motivos manifestos pelas professoras na organização do ensino de número se transformaram, pois houve uma "nova objetivação de suas necessidades, [...] compreendidas em um nível mais alto" (LEONTIEV, 2012, p. 71), isto é, a necessidade da organização do ensino passou a ser propiciar às crianças a apropriação do conceito de sistema de numeração em sua gênese, e não mais em sua aparência. Com esta transformação dos motivos, vemos que organização e as ações docentes passam a ser conscientizadas e coordenadas com os objetivos do ensino, reconhecendo que a aprendizagem de elementos dos conceitos matemáticos na infância pode acontecer por meio da brincadeira, respeitando a atividade principal da criança.

Como consequência do exposto, podemos afirmar que o conceito de $A O E$, respaldado pelos aportes teóricos da psicologia histórico-cultural (VIGOTSKI, 2007) e da Teoria da Atividade (LEONTIEV, 2012), possibilitou aos professores se constituírem e se desenvolverem em atividade de ensino num movimento de apropriação conceitual e didática, desencadeador de uma nova organização do ensino da matemática na educação que busca meios para desvelar a gênese dos conceitos e não simplesmente ensiná-los tomando apenas suas características diretamente observáveis.

Para além de constatar a potencialidade do conceito de $\mathrm{AOE}$, como propiciador de mudança da prática docente a partir de uma nova organização do ensino da matemática na Educação Infantil, o movimento de aprendizagem docente, explicitado nesta pesquisa, nos fortalece a defender que o processo de mudança da prática docente, rumo a uma educação humanizadora, é possível. Tal processo envolve uma formação docente que, embora se inicie na licenciatura, perdura por toda a vida profissional daqueles que se colocam em atividade de ensino e que ao buscarem e ressignificarem os sentidos de suas ações e práticas docentes. 


\section{MATHEMATICS IN EARLY CHILDHOOD EDUCATION: CONTRIBUTIONS OF TEACHING GUIDING ACTIVITY TO (RE) ORGANIZATION OF TEACHING PRACTICE}

ABSTRACT:This text presents a study, which investigated contributions of the concept of teaching guiding activity as a trigger of change on teaching practice in early childhood education, on the organization of teaching mathematical concepts. Theoretical framework is the historical-cultural psychology, the theory of activity and the concept of teaching guiding activity. Starting from a school context in which teachers developed mathematical activities guided only by daily and repeated situations, we developed a didactic experiment to understand the teaching learning's movement. Results indicate the potential of the concept of teaching guiding activity as a trigger of teaching practice's change through a new organization of mathematics teaching activities in early childhood education.

KEYwords: Mathematics education. Cultural-historical psychology. Teacher education. Early childhood education.

\section{MATEMÁTICAS EN LA EDUCACIÓN INFANTIL: CONTRIBUCIONES DE LA ACTIVIDAD ORIENTADORA DE ENSEÑANZA PARA LA (RE)ORGANIZACIÓN DE LA PRÁCTICA DOCENTE}

RESUMEN: Este estudio tiene el objetivo de investigar cuáles son las contribuciones del concepto de Actividad Orientadora de Enseñanza como desencadenante del cambio de la práctica docente en la Educación Infantil, en la organización de la enseñanza de nociones matemáticas. El marco teórico es la psicología Histórico-Cultural, la Teoría de la Actividad y el concepto de Actividad Orientadora de Enseñanza. A partir de un contexto escolar en el que los profesores desarrollan actividades matemáticas pautadas solo en situaciones cotidianas y repetidas, fue desarrollado un experimento didáctico para acompañar el movimiento del aprendizaje docente. Los resultados indican el potencial del concepto de Actividad Orientadora de Enseñanza como propiciador de la transformación de la práctica docente, a partir de la nueva organización de la enseñanza de las matemáticas en el Educación Infantil.

Palabras clave: Educación matemática. Psicología histórico-cultural. Formación de docentes. Educación Infantil.

\section{REFERÊNCIAS}

AMORIM, G. M. Matemática na Educação Infantil? Contribuições da Atividade Orientadora de Ensino para a (re)organização da prática docente. 2015. 187 f. Dissertação 
(Mestrado em Educação) - Faculdade de Educação. Universidade Federal de São Paulo, Guarulhos, 2015.

ARAÚJO, E. S. Da formação e do formar-se: a atividade de aprendizagem docente em uma escola pública. 2003. 173f. Tese. 2003.

CARAÇA, B. J. Conceitos Fundamentais da Matemática. Lisboa:Tipografia Matemática, 1951.

CEDRO, W. L. O motivo e a atividade de aprendizagem do professor de Matemática: uma perspectiva histórico-cultural. 2008. Tese - Universidade de São Paulo, 2008.

DIAS, M. S.; MORETTI, V. D. Números e operações: elementos lógico-históricos para atividade de ensino. Curitiba: Ibpex, 2011.

LEONTIEV, A. N. Actividad, Conciencia e Personalidad. Ciudad de La Habana: Pueblo y Educación, 1983.

Uma contribuição à teoria de desenvolvimento da psique infantil. In: VIGOTSKII, L. S. et al. Linguagem, desenvolvimento e aprendizagem. São Paulo: Ícone, 2012. p. 59-83. (Capítulo 4).

LORENZATO, S. Educação infantil e percepção matemática. Campinas: Autores Associados, 2008.

LURIA, A. R. Vigotskii. In: VIGOTSKII, L. S.; LURIA, A. R.; LEONTIEV, A. N. et al. Linguagem, desenvolvimento e aprendizagem. São Paulo: Ícone, 2012. p. 21-38. (Capítulo 2).

MORETTI, V. D. Professores de Matemática em atividade de ensino: uma perspectiva histórico-cultural para a formação docente. 2007. 208f. Tese (Doutorado em Educação) - Faculdade de Educação, Universidade de São Paulo, São Paulo, 2007.

MOURA, M. O. (Coord.). Controle da Variação de Quantidades: atividades de ensino. São Paulo: FEUSP, 1996. (Textos para o Ensino das Ciências, n. 7).

. Pesquisa colaborativa: um foco na ação formadora. In: BARBOSA, R. L. (Org.) Trajetórias e perspectivas da formação de educadores. São Paulo: Editora UNESP, 2004. p. 257-284.

. et al. Atividade Orientadora de Ensino como unidade entre ensino e aprendizagem. In: . (Org.). A atividade pedagógica na teoria histórico-cultural. Brasília: Liber livro, 2010. p. 81-110.

Didática e prática de ensino para educar com matemática. XVI ENDIPE - Encontro nacional de didática e prática de ensino - UNICAMP, Campinas: Junqueira \& Martins editores, livro 02, 2012.

; CEDRO, W. L. Possibilidades metodológicas na pesquisa em educação matemática: o experimento didático. Revista Educativa, Goiânia, v. 15, n. 1, p. 25-38, jan./jun. 2012. Disponível em: <http://seer.ucg.br/index.php/educativa/article/ view/2439/1501 $\geq$. Acesso em: 14 ago. 2014. 
RIBEIRO, F. D. A aprendizagem da docência na pratica de ensino e no estágio: contribuições da teoria da atividade. 2011. 196 f. Tese (Doutorado em Educação) - Faculdade de Educação, Universidade de São Paulo, São Paulo, 2011.

VIGOTSKI, L. S. A formação social da mente. Tradução José Cipolla Neto, Luis Silveira, Menna Bareto, Solange Castro Afeche. 7 ed. São Paulo: Martins Fontes, 2007.

. Vigotski: a construção do pensamento e da linguagem. Tradução Paulo Bezerra. 2. ed. São Paulo: Martins Fontes, 2009.

Gisele Mendes AmORIM: Mestre em Educação pela Universidade Federal de São Paulo (UNIFESP), graduada em Pedagogia pela Universidade Estadual Paulista Júlio de Mesquita Filho (UNESP). Atua como diretora de escola municipal e realiza pesquisas na área de formação de professores na perspectiva histórico-cultural e participa do Grupo de Estudos e Pesquisa em Processos Educativos e Perspectiva Histórico- Cultural da UNIFESP.

E-mail: siselemamorim@hotmail.com

VANESSA DiAs MORETt: Doutora em Educação pela Faculdade de Educação da Universidade de São Paulo (Ensino de Ciências e Matemática). Professora Adjunta IV na Universidade Federal de São Paulo (UNIFESP) e professora credenciada no Programa de Pós-Graduação em Educação (PPGE) na mesma instituição. Pesquisadora do Grupo de Estudos e Pesquisas sobre a Atividade Pedagógica (GEPAPe/USP) e líder do Grupo de Estudos e Pesquisa em Processos Educativos e Perspectiva Histórico Cultural (GEPPEDH/ UNIFESP). Desenvolve pesquisas em Educação Matemática focando especialmente a formação inicial e continuada de professores que ensinam matemática, aprendizagem da docência, atividade de ensino e teoria histórico-cultural.

E-mail: vanessadmoretti@gmail.com 